\title{
Oral diseases and socio-demographic factors in adolescents living in Maasai population areas of Tanzania: a cross-sectional study
}

\author{
Lutango D. Simangwa ${ }^{1 *}$ (D) Anne N. Åstrøm², Anders Johansson³ ${ }^{3}$ Irene K. Minja ${ }^{4}$ and Ann-Katrin Johansson ${ }^{1}$
}

\begin{abstract}
Background: Oral diseases may cause serious health problems, especially in socially disadvantaged populations and in low-income countries. In populations living in the rural areas of Tanzania there is paucity of reports on oral health. The study aim was to estimate the prevalence, severity and socio-demographic distribution of oral diseases/conditions in adolescents living in Maasai population areas of Tanzania and to compare oral diseases/conditions between Maasai and non-Maasai ethnic groups.
\end{abstract}

Methods: A total of 23 schools were randomly selected from 66 rural public primary schools in Monduli and Longido districts, Tanzania. All pupils in the selected classes, 6th grade, were invited to participate in the study. A total of 989 were invited and 906 (91.6\%) accepted the invitation and completed an interview and a clinical oral examination.

Results: Out of 906 study participants (age range 12-17 years), $721(79.6 \%)$ were from Maasai and 185 (20.4\%) from non-Maasai ethnic groups. Prevalence of poor oral hygiene, gingival bleeding, dental caries experience (DMFT>0), dental fluorosis TF grade 5-9, dental erosion (into dentin), tooth wear (into dentin) and TMD was $65.6,40.9,8.8,48.6,1.9,16.5$ and $11.8 \%$, respectively. Multiple variable logistic regression analysis revealed that, girls $(O R=2.0)$ and participants from Longido $(O R=2.6)$ were more likely to present with good oral hygiene $(p<0.05)$. Adolescents from Monduli $(\mathrm{OR}=1.7)$, males $(\mathrm{OR}=2.1)$, being born within Arusha region $(\mathrm{OR}=1.9)$ and Maasai $(\mathrm{OR}=1.7)$ were more likely to present with gingival bleeding $(p<0.05)$. DMFT> 0 increased by age $(\mathrm{OR}=2.0)$ and was associated with non-Maasai ethnic group $(\mathrm{OR}=2.2)$, $(p<0.05)$. Adolescents from Monduli district $(\mathrm{OR}=10.0)$ and those born in Arusha region $(\mathrm{OR}=3.2)$ were more likely to present with dental fluorosis $(p<0.05)$. Dental erosion was more common among non-Maasais $(O R=2.0)$ as well as having mother with high education $(O R=2.3),(p<0.05)$.

Conclusions: Oral diseases like dental caries and dental erosion were less common, but gingival bleeding, dental fluorosis, tooth wear and TMD were common findings in adolescents attending primary schools in the Maasai population areas of Tanzania. Notable differences between Maasai and non-Maasai ethnic groups and certain correlations to sociodemographic factors were detected. Our findings can be utilized by policy makers in the planning of oral health programs in public primary schools of Maasai population areas of Tanzania.

Keywords: Adolescents, Dental caries, Dental erosion, Dental fluorosis, Maasai population areas, Oral hygiene, Temporomandibular disorders, Tooth wear

\footnotetext{
*Correspondence: Lutango.Simangwa@uib.no

'Department of Clinical Dentistry Cariology, Faculty of Medicine, University of

Bergen, Bergen, Norway

Full list of author information is available at the end of the article
}

(c) The Author(s). 2018 Open Access This article is distributed under the terms of the Creative Commons Attribution 4.0 International License (http://creativecommons.org/licenses/by/4.0/), which permits unrestricted use, distribution, and reproduction in any medium, provided you give appropriate credit to the original author(s) and the source, provide a link to the Creative Commons license, and indicate if changes were made. The Creative Commons Public Domain Dedication waiver (http://creativecommons.org/publicdomain/zero/1.0/) applies to the data made available in this article, unless otherwise stated. 


\section{Introduction}

Oral diseases are among the most common diseases and yet it is not unusual that these type of problems receive little attention especially so in countries with weak health care systems [1]. Most countries in sub-Saharan Africa, for example Tanzania, focus on high mortality diseases like HIV/ AIDS, cancer, tuberculosis, diabetes and malaria and pay less attention to oral health issues [2]. In many regions it is therefore common that oral diseases, such as dental caries, are left untreated or at the best treated with tooth extraction as the only choice for emergency treatment [3]. The remote population in Tanzania is more or less excluded from oral health services. To improve the access to general health care for pastoralists in the northern part of Tanzania, to a large extent including the Maasai tribe, village dispensaries/health centers have been placed in specific areas [4]. However, due to the pastoral lifestyle of these groups of people, which implies living and moving together with their animals, this special service has been of limited use [4].

A relation between oral diseases/conditions and sociodemographic factors such as sex, age, education, ethnicity and wealth/family income have been reported worldwide [5-10]. Studies have shown that children from lower-income households are more likely to experience dental caries than their economically more advantaged counterparts [11-13]. It is also clear that children of parents with high education experience less dental caries than children of parents with low education [12, 14]. Considering sex and age, findings from sub-Saharan Africa have shown a consistent pattern in which dental caries experience is not only significantly greater in females, but also increases with age [15-18]. Studies from sub-Saharan Africa have also shown that the prevalence of dental caries often is low and the mean DMFT of 14 year olds living in rural areas of Tanzania (2010), 12 year olds in Kenya (2012), and 10-14 year olds in Uganda (2003) has been found to be $0.3,0.4$ and 0.7 , respectively [19-21]. Besides this, one older study as far back as 1931 and another more recent study from 1997 are addressing mainly the medical health of the pastoral societies in Sub-Saharan Africa but also including a few oral health parameters reported that the occurrence of dental caries among the Maasais at that time was lower than in the other groups $[22,23]$.

Poor oral hygiene have commonly been reported among both children and adolescents and may lead to a number of oral health problems such as dental caries, gingivitis, periodontitis and tooth loss [24, 25]. For example in Zambia, the prevalence of poor oral hygiene in 10-14 year old adolescents (2011) was $10 \%$ and in Nigeria the corresponding figures among 11-14 years olds was found to be 32\% (2011) [26, 27]. Among adolescents in Tanzania, the prevalence of poor oral hygiene was found to be as high as $65-99 \%(1988,1996)$ and the occurrence of gingivitis as high as $80-90 \%[28,29]$.
Reports from the Eastern part of sub-Saharan Africa show that dental fluorosis is very common and in certain regions its prevalence has been found to be nearly $100 \%$ $[30,31]$. The prevalence of more severe dental fluorosis according to Thylstrup Fejerskov index (TF-index) grade $\geq 5$ in Kenyan adolescents 13-15 year olds was found to be $48 \%$ in 2009 [32]. In the Northern part of Tanzania, the concomitant corresponding prevalence in 10-14 year olds (2000) varied between 10 and 34\% [33].

The presence of more severe dental erosion in adolescents in many parts of the world has been reported with varying prevalence (3-26\%) [34-38]. To our knowledge no studies on dental erosion have been performed in sub-Saharan African adolescents. The literature on tooth wear in general in the Sub-Saharan populations is scarce and focused mainly on adults. A study in the Sudanese population aged 16-75 years and older (2012) found that $26 \%$ of the population had tooth wear [39] and a corresponding figure from Nigeria (2010) among of 20-64 year olds was 53\% [40].

Temporomandibular disorders (TMD) are a significant public health problem worldwide affecting 3 to $11 \%$ depending on diagnosis [41]. Studies on TMD in sub-Saharan Africa are rare, however studies from Nigeria and Tanzania found that $26 \%$ of the Nigerian young adults and $67 \%$ of the Tanzanian adults had some evidence of signs and symptoms of TMD [42, 43]. Reports from other parts of the world using the research diagnostic criteria (RDC/TMD) are reporting diverging figures. For example among 10-18 year olds, studies in Sweden (1999 and 2009) found that 5$9 \%$ of the participants had TMD $[44,45]$ and in a Saudi Arabian study (2016) it was found that one third of the participants had at least one TMD diagnosis [46]. Among adolescents and young adults in a Mexican study conducted in 2006 it was reported that the prevalence of some grade of TMD was as high as $46 \%$ [47].

To the best of our knowledge, there is no information on the oral diseases of contemporary adolescents living in Maasai population areas in Arusha region, northern Tanzania. Thus, the aim of this study was to estimate the prevalence, severity and socio-demographic distribution of oral diseases/conditions in adolescents living in Maasai population areas of Tanzania. It also aimed to explore whether the socio-demographic differences in oral diseases/problems varied according to Maasai and non-Maasai ethnicity.

\section{Methods}

\section{Sample size}

The sample size was estimated based on the assumption that the prevalence of dental erosion among adolescents was $50 \%$. The estimated minimum sample size for this study, 845 adolescents, was obtained by assuming a margin error of $5 \%$ and, confidence intervals of $95 \%$. Furthermore, 
the sample size was multiplied by 2 to account for the design effect (D), and increased by $10 \%$ to account for contingencies such as non-response or recording errors.

\section{Sampling technique}

A cross-sectional study was carried out in Maasai population areas of Monduli and Longido districts, in the Arusha region, in the northern part of Tanzania from June to November 2016. The study aimed to focus on 12-14-year-old adolescents, attending rural public primary schools. A list of all primary schools comprising public (urban and rural) and private schools (total of 100 schools) was obtained from both districts. After having excluded urban and private schools, 23 (13 from Monduli and 10 from Longido) out of a total of 66 (38 from Monduli and 28 from Longido) eligible rural public primary schools were randomly selected using a one-stage cluster sample design with school as the primary sampling unit and random number generator software. In each randomly selected school, a class expected to contain adolescents aged 12-14 years was purposively identified (6th grade). All children available in the identified class were invited to participate in the study. Thus, the inclusion criteria were adolescents expected to be in age 12 to 14 year old attending rural public primary schools of Monduli and Longido districts. The exclusion criteria were adolescents attending urban and private primary schools, those absent during the interview/oral examination day and those with learning difficulties.

\section{Interviews}

The questionnaire was constructed in English, translated into Swahili and back-translated to English independently by qualified translators from the University of Dar Es Salaam, Tanzania. Closed- and open-ended questions were used to gather information.

Pre-testing of the questionnaire took place in fifty primary school children (12-14 year olds) before the actual fieldwork regarding wording, meaning, and content of each item, and appropriateness of format and modified as needed. Two especially trained medical nurses performed face-to-face interviews in Swahili/Maa (Maasai language) with each adolescent. Face-to-face interview was done in a school setting, either under the tree or inside the classroom depending on availability and each child was interviewed privately while others were inside their classes. In this study, the pilot participants were not part of the main study.

Socio-demographic factors were assessed in terms of age, ethnicity, sex, place of residence (place of residence was defined as the district where an adolescent was living in e.g., Monduli or Longido districts), father's and mother's education, house ownership, number of children, household socio-economic status (perceived affluence of my household) and household wealth index [48]. For the purpose of assessing their wealth index, their livestock were not included because we used Principal Component Analysis (PCA) in calculating the wealth index and PCA works best when the household asset variables are correlated, but also works best when the distribution of variables varies across the households. It is those assets that are more unequally distributed between households that are given more weight in PCA [49]. Variables with low standard deviations carry a low weight from PCA. For example an asset which is owned by almost all households would exhibit no variation between households and would be zero weighted and thus of no use in differentiating the wealth of a particular family. In our study livestock were owned by the majority (93\%) of their families, and so livestock was of little or no use in differentiating their wealth. Ethnicity was assessed by asking "what is your ethnic group?" The response categories were $(1)=$ Maasai, $(2)=$ Meru, (3) = Arusha and (4) = others. For analysis, the items were dichotomized to $1=$ Maasai (including option (1)) and 2 = non Maasai (including option (2), (3) and (4) during analysis.

Parents' education was assessed by asking what is the highest level of school your mother/father has attended? Responses were (0) for none, (1) for she/he started but did not complete primary school, (2) for completed primary school (3) for she/he started but did not complete secondary school, (4) for she/he completed secondary school, (5) for she/he started but did not complete college/university, (6) for completed college/university, (7) for I don't know. In the statistical analyses, the items were dichotomized as (0) for low education (from options (0), (1), (2), (3) and (7) and (1) for high education (from options (4), (5) and (6).

Durable household assets indicative of family wealth (i.e. radio, television, refrigerator, mobile telephone, cupboard, bicycle and motorcycle) was recorded as (Yes) "available and in working condition" or (No) "not available and/or not in working condition." The TMD epidemiological questions were Do you have pain in your temple, face, jaw or jaw joint once a week or more? Does it hurt once a week or more when you open your mouth or chew? The response was either yes or no and positive answer to any of the two questions is considered affirmative to TMD diagnosis [50].

\section{Clinical examination}

After an interview, clinical oral examinations were performed by the principal investigator (L.S). The child was examined under field conditions outside or inside the classroom sitting on a chair in natural day light, avoiding the direct sun light. When necessary, the teeth were cleaned and dried by sterile gauze and isolated by cotton rolls. Disposable mouth mirrors and sickle probes (No. 23 explorer or Shepherd's hook) were used. 
Oral hygiene was assessed using the Simplified Oral Hygiene Index (OHI-S) [51]. The scores were (0) for no plaque/calculus present, (1) for plaque or supra-gingival calculus covering not more than one third of the tooth surface, (2) for plaque or supra-gingival calculus covering more than one third but less than two thirds of the tooth surface, and (3) for plaque or supra-gingival calculus covering more than two thirds of the tooth surface. For each individual, the plaque and calculus scores were summed up and divided by total number of teeth examined to obtain the Simplified Debris Index (DI-S) and simplified calculus index (CI-S). The OHI-S was constructed by summing up the DI-S and CI-S. During analysis the OHI-S scores were dichotomized into $1=$ good oral hygiene $(\mathrm{OHI}-\mathrm{S}<1)$ and $2=$ poor oral hygiene $(\mathrm{OHI}-\mathrm{S} \geq 1)$.

Gingival health was assessed by Gingival Bleeding Index (GBI) [52]. Dental caries was assessed according to criteria specified by WHO, 2013 [53] and dental fluorosis was assessed by Thylstrup- Fejerskov - index (TF-index) [54]. Dental erosion on palatal and facial surfaces of maxillary anterior teeth was recorded according to Johansson et al. 1996 [55] and grading of first molar cuppings by Hasselkvist et al. [37]. Tooth wear was graded as a full mouth recording of occlusal/incisal surfaces according to Carlsson et al. [56].

\section{Statistical analysis}

Data were analyzed using the Statistical Package for Social Sciences (SPSS) for PC, version 24 (IBM corporation, Armonk, NY, USA). STATA 14.2 (Stata corporation, Lakeway drive college station, Texas, USA) was used to adjust for the cluster effect of school. Principle component analysis was used to construct a socio-economic index categorized into wealth quintiles (1st quartile, 2nd quartile, 3rd quartile and 4th quartile implying the poorest, poorer, less poor and least poor respectively) and based on ownership of assets such as furniture and household characteristics including electricity, type of water source roof material and toilet types [48]. Descriptive statistics was carried out followed by bivariate analysis using cross tabulations and Pearson's chi-square statistical test. Multiple variable logistic regression analysis (Odds Ratio and 95\% CI) was carried out with all socio-demographic variables that were statistically significantly associated with oral hygiene status, gingival bleeding, dental caries, dental fluorosis, dental erosion/tooth wear, and TMD in Pearson's chi-square test (unadjusted analysis) were included in the model simultaneously. For each outcome variables, there were two levels/categories used in the multiple variable logistic regression analysis. For instance, oral hygiene status was dichotomized into $0=$ poor oral hygiene and $1=$ good oral hygiene; gingival bleeding was dichotomized into $0=$ without bleeding and 1 =with bleeding; dental caries was dichotomized into DMFT $=0$ and DMFT $>0$ and dental fluorosis was dichotomized into $0=$ TF score $0-4$ and $1=$
TF score 5-9. In addition, Dental erosion was dichotomized into $0=$ grade 0 and $1=$ grade $1-4$; tooth wear was dichotomized into $0=$ grade 0 and $1=$ grade $1-4$; and TMD was dichotomized into $0=$ without TMD symptoms and $1=$ with TMD symptoms.

\section{Results}

\section{Sample characteristics}

A total of 989 grade 6 primary school adolescents were invited to participate in the study. Of those, 930 adolescents accepted to participate. Twenty-four (2.6\%) children who attended the study were excluded during analysis due to too high or low age. Thus, the study included 906 children $12-17$ years, mean age 13.4 years (SD 1.2) of which $56.1 \%$ were females. The final response rate was $91.6 \%$. Among the participants, $52.9 \%$ were from Monduli district and the remaining from Longido district. Of the participants $79.6 \%$ were from the Maasai ethnic group and the remaining $20.4 \%$ from the non-Maasai group.

\section{Reliability}

Duplicate clinical examinations (intra-examiner concordance, LS), 3 weeks apart, were carried out with 93 randomly selected participants. Analysis performed on duplicate examination records revealed Kappa value of 0.98, 0.87, and 0.69 for DMFT, TF-index, and dental erosion respectively. Higher Kappa values for DMFT and TF-index might have been contributed by the examiners common knowledge about the disease/condition in the population being rated [57].

\section{Socio-demographic characteristics by ethnicity}

As depicted in Table 1, mothers who reported secondary school education level or above were $3.2 \%$ for the Maasais and $11.9 \%$ for the non-Maasais $(p<0.001)$. All sociodemographic characteristics except sex and age group differed statistically significantly between the two ethnic groups.

\section{Prevalence, severity of oral diseases/conditions and correlated sociodemographic factors}

The overall prevalence of poor oral hygiene (OHI-S $\geq 1)$ was $65.6 \%$ (good oral hygiene was $34.4 \%$ ) and gingival bleeding was $40.9 \%$. As depicted in Table 2 oral hygiene status and gingival bleeding varied statistically significantly according to district, sex, age group, birth region and ethnicity $(p<0.05)$. Good oral hygiene was more common among the non-Maasai adolescents $(45.9 \%)$ than the Maasai adolescents (31.5\%). A total of $27.4 \%$ of the males and $40.0 \%$ of the females had good oral hygiene $(p<0.05)$. Similarly, gingival bleeding was more common in Maasai adolescents (44.4\%) than non-Maasai $(27.6 \%)(p<0.05)$. 
Table 1 Socio-demographic characteristics by ethnic groups

\begin{tabular}{|c|c|c|c|c|}
\hline Variable & Categories & Maasai \% (n) & Non-Maasai \% (n) & $p$-value \\
\hline \multirow[t]{2}{*}{ District } & Monduli & $58.0(418)$ & $33.0(61)$ & \\
\hline & Longido & $42.0(303)$ & $67.0(124)$ & $<0.001^{*}$ \\
\hline \multirow[t]{2}{*}{ Sex } & Male & $43.1(311)$ & $47.0(87)$ & \\
\hline & Female & $56.9(410)$ & $53.0(98)$ & 0.341 \\
\hline \multirow[t]{2}{*}{ Age group } & $12-14$ years & $86.5(610)$ & $90.3(167)$ & \\
\hline & $15-17$ years & $13.5(95)$ & $9.7(18)$ & 0.173 \\
\hline \multirow[t]{4}{*}{ Wealth index } & 1st quartile (poorest) & $29.4(209)$ & $7.0(13)$ & \\
\hline & 2nd quartile (very poor) & 27.9 (199) & $9.2(17)$ & \\
\hline & 3rd quartile (less poor) & $28.5(203)$ & $12.4(23)$ & \\
\hline & 4th quartile (least poor & $14.2(101)$ & $71.4(132)$ & $<0.001^{*}$ \\
\hline \multirow[t]{2}{*}{ Region of Birth } & Arusha & $99.0(714)$ & $78.4(145)$ & \\
\hline & Others & $1.0(7)$ & $21.6(40)$ & $<0.001^{*}$ \\
\hline \multirow[t]{2}{*}{ Mother's education } & Low ( $\leq$ primary school) & $96.8(698)$ & $88.1(163)$ & \\
\hline & High ( $\geq$ secondary school) & $3.2(23)$ & $11.9(22)$ & $<0.001^{*}$ \\
\hline \multirow[t]{2}{*}{ Father's education } & Low ( $\leq$ primary school) & $95.0(685)$ & 80.5 (149) & \\
\hline & High ( $\geq$ secondary school) & $5.0(36)$ & $19.5(36)$ & $<0.001^{*}$ \\
\hline \multirow[t]{2}{*}{ House ownership } & Yes & $98.6(711)$ & $80.0(148)$ & \\
\hline & No & $1.4(10)$ & $20.0(37)$ & $<0.001^{*}$ \\
\hline \multirow[t]{2}{*}{ Number of children } & $1-5$ children & $45.1(325)$ & $63.8(118)$ & \\
\hline & 6-14 children & $54.9(396)$ & $36.2(67)$ & $<0.001^{*}$ \\
\hline
\end{tabular}

*Significant Pearson's Chi-square test $(p<0.05)$

Maasai $n=721$, non-Maasai $n=185$

Dental caries prevalence (DMFT>0) was $8.8 \%$. The overall mean DMFT was 0.13 (SD 0.5). The DMFT was composed of the decayed $(\mathrm{D}=90.0 \%)$, missing teeth due to caries $(\mathrm{M}=5.0 \%)$ and filled teeth $(\mathrm{F}=0)$. Adolescents with both, decayed and missing teeth due to caries were $5.0 \%$. The overall mean DMFS was 0.22 (SD 0.9). The mandibular first permanent molar was the most commonly registered tooth with dental caries $(60.0 \%)$ and the occlusal surface was the most common registered site with caries (71.6\%). As shown in Table 3, 7.4\% of the Maasai adolescents had a DMFT $>0$ and the corresponding figures for the non-Maasai was $14.6 \%(p<0.05)$. Among the 12-14 year old adolescents, a total of 8.2 and $13.3 \%$ of the $15-17$ year old adolescents had DMT $>0$ $(p<0.05)$.

Dental fluorosis, TF grade 1-9, was recorded in $89.7 \%$ of the participants and more severe fluorosis TF-grade 59 in $48.6 \%$. More severe dental fluorosis (TF grade 5-9) was more common among the Maasai than non-Masaai (52.1 and $34.6 \%$ respectively, $p<0.05$ ). About $51 \%$ of the adolescents born in Arusha region was registered with severe dental fluorosis TF score $5-9$, while only $12.8 \%$ of the adolescents born outside Arusha region $(p<0.05)$ had so.

Figure 1 shows the percentage distributions of adolescents according to maximum TF score per subject by ethnic groups. Dental fluorosis, TF grade 1-9, was more common and more severe among the Maasai adolescents (97.6\%) than the non-Maasai (58.9\%).

Dental erosion extending into dentine (grade 3-4) was registered in $1.9 \%$ (grade $1-4$ was $30.0 \%$ ) of the participants and tooth wear extending into dentine (grade 2-4) in $16.5 \%$ (grade 1-4 was $44.3 \%$ ). As shown in Table 4 dental erosion was less common among the Maasai- than the non-Maasai- adolescents since 26.8 and $43.8 \%$, respectively showed any grade of erosion (grade $1-4)(p<0.05)$. Furthermore, dental erosion was registered among $24.0 \%$ of the adolescents from Monduli districts and $36.8 \%$ of the adolescents from Longido districts $(p<0.05)$. However, none of them was registered with the most severe grade of dental erosion (grade 4). In general, the pattern of tooth wear was more similar across the ethnic groups and $44.9 \%$ of the Maasais and $50.3 \%$ of the non-Maasais was registered with some type of tooth wear $(p>0.05)$.

TMD pain (TMD-p) was found in $11.8 \%$ of the participants. The prevalence of TMD among Maasais and nonMaasais was 11.2 and $14.1 \%$ respectively $(p>0.05)$.

Socio-demographic variables found statistically significantly associated with oral diseases and problems in unadjusted analysis (Tables 2, 3 and 4) were entered simultaneously, into seven separate multiple variable logistic regression models in order to investigate the likelihood of having good oral hygiene, gingival bleeding, dental caries 
Table 2 Frequency distribution of oral hygiene status and bleeding gums by socio-demographic factors

\begin{tabular}{|c|c|c|}
\hline Variable & $\begin{array}{l}\text { Oral hygiene status } \\
\% \text { Good (n with } \\
\text { OHI-S }<1 \text { ) }\end{array}$ & $\begin{array}{l}\text { Gingival Bleeding } \\
\%(n)\end{array}$ \\
\hline Prevalence (whole sample) & $34.4(312)$ & $40.9(371)$ \\
\hline \multicolumn{3}{|l|}{ District } \\
\hline Monduli & $24.6(118)$ & $47.4(227)$ \\
\hline Longido & $45.4(194)^{*}$ & $33.7(144)^{*}$ \\
\hline \multicolumn{3}{|l|}{ Sex } \\
\hline Male & $27.4(109)$ & $50.3(200)$ \\
\hline Female & $40.0(203)^{*}$ & $33.7(171)^{*}$ \\
\hline \multicolumn{3}{|l|}{ Age group } \\
\hline $12-14$ & $35.9(279)$ & $38.6(300)$ \\
\hline $15-17$ & $23.9(27)^{*}$ & $56.6(64)^{*}$ \\
\hline \multicolumn{3}{|l|}{ Region of Birth } \\
\hline Arusha & $33.6(288)$ & $42.3(363)$ \\
\hline Others & $48.9(23)^{*}$ & $17.0(8)^{*}$ \\
\hline \multicolumn{3}{|l|}{ Ethnicity } \\
\hline Maasai & $31.5(213)$ & $44.4(320)$ \\
\hline Non-maasai & $45.9(85)^{*}$ & $27.6(51)^{*}$ \\
\hline \multicolumn{3}{|l|}{ Wealth index } \\
\hline 1st quartile (poorest) & $29.3(65)$ & $44.6(99)$ \\
\hline 2nd quartile (very poor) & $28.2(61)$ & $48.1(104)$ \\
\hline 3rd quartile (less poor) & $30.5(69)$ & $42.0(95)$ \\
\hline 4th quartile (least poor) & $47.2(110)^{*}$ & $30.9(72)$ \\
\hline \multicolumn{3}{|l|}{ Mother's education } \\
\hline Low ( $\leq$ primary school) & $33.9(292)$ & $41.7(359)$ \\
\hline High ( $\geq$ secondary school) & $44.4(20)$ & $26.7(12)^{*}$ \\
\hline \multicolumn{3}{|l|}{ Father's education } \\
\hline Low ( $\leq$ primary school) & $34.1(285)$ & $41.2(344)$ \\
\hline High ( $\geq$ secondary school) & $38.9(28)$ & $37.5(27)^{*}$ \\
\hline
\end{tabular}

*Significant Pearson Chi-square test $(p<0.05)$

experience (DMFT $>0$ ), dental fluorosis TF grade $5-9$, dental erosion (grade 1-4), tooth wear (grade 1-4), and TMD $(2 \mathrm{Q} / \mathrm{TMD}>0)$. As shown in Table 5, adolescents from Longido district were 2.6 times $(\mathrm{OR}=2.6, \mathrm{CI} 1.6-4.4)$ more likely to have good oral hygiene compared to adolescents from Monduli district. Females were $2.0(\mathrm{OR}=2.0$, CI 1.4$2.5)$ times more likely to have good oral hygiene compared to males. Adolescents from Longido district, females and non Maasai were respectively 0.6-times $(\mathrm{OR}=0.6$, CI 0.4 $0.8)$, 0.5-times (OR $=0.5$, CI $0.4-0.6)$ and $0.6(0.4-0.9)$ times less likely to have gingival bleeding compared to their counterparts in Monduli district, males and Maasais. Adolescents born within the Arusha region and older age groups were 2.0-times $(\mathrm{OR}=2.0$, CI 1.2-3.3) and $1.6(1.0-$ 2.5) more likely to have gingival bleeding compared to those born outside Arusha and younger age group. Statistically
Table 3 Frequency distribution of dental caries experience (DMFT >0) and severe dental fluorosis (TF grade 5-9) by socio-demographic factors

\begin{tabular}{|c|c|c|}
\hline Variable & DMFT > 0 \% (n) & Dental fluorosis \% (n) \\
\hline Prevalence (whole sample) & $8.8(80)$ & $48.6(440)$ \\
\hline \multicolumn{3}{|l|}{ District } \\
\hline Monduli & $10.0(48)$ & 77.8 (339) \\
\hline Longido & $7.5(32)$ & $23.7(101)^{*}$ \\
\hline \multicolumn{3}{|l|}{ Sex } \\
\hline Male & $9.5(38)$ & $47.2(188)$ \\
\hline Female & $8.3(42)$ & $49.6(252)$ \\
\hline \multicolumn{3}{|l|}{ Age group } \\
\hline $12-14$ & $8.2(64)$ & $46.3(360)$ \\
\hline $15-17$ & $13.3(15)^{*}$ & $63.7(72)^{*}$ \\
\hline \multicolumn{3}{|l|}{ Region of Birth } \\
\hline Arusha & $8.4(72)$ & $50.5(434)$ \\
\hline Others & $17.0(8)$ & $12.8(6)^{*}$ \\
\hline \multicolumn{3}{|l|}{ Ethnicity } \\
\hline Maasai & $7.4(53)$ & $52.1(376)$ \\
\hline Non-maasai & $14.6(27)^{*}$ & $34.6(64)^{*}$ \\
\hline \multicolumn{3}{|l|}{ Wealth index } \\
\hline 1st quartile (poorest) & $7.7(17)$ & 49.1 (109) \\
\hline 2nd quartile (very poor) & $6.9(15)$ & $59.3(128)$ \\
\hline 3rd quartile (less poor) & $10.2(23)$ & $56.2(127)$ \\
\hline 4th quartile (least poor) & $10.7(25)$ & $30.9(72)^{*}$ \\
\hline \multicolumn{3}{|l|}{ Mother's education } \\
\hline Low ( $\leq$ primary school) & $8.8(76)$ & $49.2(424)$ \\
\hline High ( $\geq$ secondary school) & $8.9(4)$ & $35.6(16)$ \\
\hline \multicolumn{3}{|l|}{ Father's education } \\
\hline Low ( $\leq$ primary school) & $8.9(74)$ & $49.0(409)$ \\
\hline High ( $\geq$ secondary school) & $8.3(6)$ & $43.1(31)$ \\
\hline
\end{tabular}

*Significant Pearson Chi-square test $(p<0.05)$

significant two-way interactions occurred between ethnicity and wealth index on oral hygiene status whereby adolescents from non Maasais and least poor families were $2.8(\mathrm{OR}=$ 2.8, CI 1.1-7.2) times more likely to have good oral hygiene compared to those from Maasais and most poor families. Female adolescents from non Maasai were $2.5(\mathrm{OR}=2.5, \mathrm{CI}$ 1.2-5.4) times more likely to have gingival bleeding compared to males from Maasais group. As shown in Table 6, older aged $(\mathrm{OR}=2.0$, CI 1.1-3.5) and non-Maasai adolescents $(\mathrm{OR}=2.2$, CI 1.1-4.1) were more likely to have DMFT $>0$ compared to the younger aged and Maasai adolescents, respectively. Adolescents from Longido district $(\mathrm{OR}=0.1, \mathrm{CI} 0.1-0.3)$ were less likely to have dental fluorosis TF grade 5-9 than children from Monduli district. Moreover, adolescents born within the Arusha region $(\mathrm{OR}=3.2$, CI 1.0-10.2) were 3.2-times more likely to have dental fluorosis TF grade 5-9 than those born 


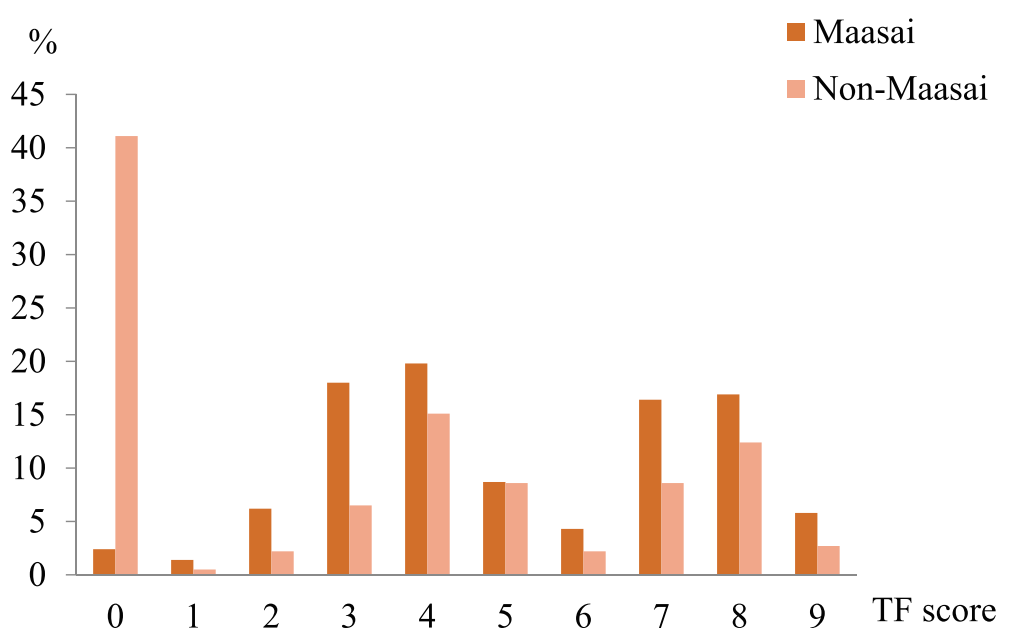

Fig. 1 Percentage distributions of children with dental fluorosis according to maximum TF score per subject by ethnic groups. Maasai $n=721$; non-Maasai $n=185$

Table 4 Frequency distribution of dental erosion (grade 1-4), tooth wear (grade 1-4) and TMD by socio-demographic factors

\begin{tabular}{|c|c|c|c|}
\hline Variable & Dental erosion \% (n) & Tooth wear \% (n) & TMD $>0 \%(n)$ \\
\hline Prevalence (whole sample) & $30.0(372)$ & $44.3(401)$ & $11.8(107)$ \\
\hline \multicolumn{4}{|l|}{ District } \\
\hline Monduli & $24.0(115)$ & $42.8(205)$ & $18.0(86)$ \\
\hline Longido & $36.8(157)^{*}$ & $45.9(196)$ & $4.9(21)^{*}$ \\
\hline \multicolumn{4}{|l|}{ Sex } \\
\hline Male & $28.1(112)$ & $46.0(183)$ & $12.3(49)$ \\
\hline Female & $31.5(160)$ & $42.9(218)$ & $11.4(58)$ \\
\hline \multicolumn{4}{|l|}{ Age group } \\
\hline $12-14$ & $30.4(236)$ & $43.8(340)$ & $11.2(87)$ \\
\hline $15-17$ & $28.3(32)$ & $48.7(55)$ & $17.7(20)^{*}$ \\
\hline \multicolumn{4}{|l|}{ Region of Birth } \\
\hline Arusha & $29.2(251)$ & $44.7(384)$ & $11.9(102)$ \\
\hline Others & $47.7(21)^{*}$ & $36.2(17)$ & $10.6(5)$ \\
\hline \multicolumn{4}{|l|}{ Ethnicity } \\
\hline Maasai & 26.8 (193) & $44.9(324)$ & $11.2(81)$ \\
\hline Non-maasai & $43.8(81)^{*}$ & $50.3(92)$ & $14.1(26)$ \\
\hline \multicolumn{4}{|l|}{ Wealth index } \\
\hline 1st quartile (poorest) & $29.7(66)$ & $28.6(113)$ & $12.2(27)$ \\
\hline 2nd quartile (very poor) & $25.5(55)$ & $23.0(91)$ & $8.8(19)$ \\
\hline 3rd quartile (less poor) & $20.8(47)$ & $21.5(85)$ & $13.3(30)$ \\
\hline 4th quartile (least poor) & $42.9(100)^{*}$ & $26.8(106)^{*}$ & $12.9(30)$ \\
\hline \multicolumn{4}{|l|}{ Mother's education } \\
\hline Low ( $\leq$ primary school) & $28.8(248)$ & $44.5(383)$ & $10.8(93)$ \\
\hline High ( $\geq$ secondary school) & $53.3(24)^{*}$ & $40.0(18)$ & $31.1(14)^{*}$ \\
\hline \multicolumn{4}{|l|}{ Father's education } \\
\hline Low ( $\leq$ primary school) & $29.4(245)$ & $44.2(369)$ & $11.6(97)$ \\
\hline High ( $\geq$ secondary school) & $37.5(27)$ & $44.4(32)$ & $13.9(10)$ \\
\hline
\end{tabular}


Table 5 Oral hygiene status and gingival bleeding regressed on socio-demographic characteristics and statistically significant interactions

\begin{tabular}{|c|c|c|c|c|}
\hline \multirow[t]{2}{*}{ Variable } & \multicolumn{2}{|c|}{ Oral hygiene status (Good oral hygiene) } & \multicolumn{2}{|c|}{ Gingival bleeding } \\
\hline & $\mathrm{OR}(95 \% \mathrm{Cl})$ & $P$ & $\mathrm{OR}(95 \% \mathrm{Cl})$ & $P$ \\
\hline \multicolumn{5}{|l|}{ District } \\
\hline Monduli & 1 & & 1 & \\
\hline Longido & $2.6(1.6-4.4)$ & $<0.001$ & $0.6(0.4-0.8)$ & 0.002 \\
\hline \multicolumn{5}{|l|}{ Sex } \\
\hline Male & 1 & & 1 & \\
\hline Female & $2.0(1.4-2.5)$ & $<0.001$ & $0.5(0.4-0.6)$ & $<0.001$ \\
\hline \multicolumn{5}{|l|}{ Age group } \\
\hline $12-14$ years & 1 & & 1 & \\
\hline $15-17$ years & $0.8(0.4-1.5)$ & 0.519 & $1.6(1.0-2.5)$ & 0.053 \\
\hline \multicolumn{5}{|l|}{ Region of birth } \\
\hline Others & 1 & & 1 & \\
\hline Arusha & $1.0(0.7-1.5)$ & 0.794 & $2.0(1.2-3.3)$ & 0.005 \\
\hline \multicolumn{5}{|l|}{ Ethnic groups } \\
\hline Maasai & 1 & & 1 & \\
\hline Non-Maasai & $1.4(0.9-2.4)$ & 0.140 & $0.6(0.4-0.9)$ & 0.008 \\
\hline \multicolumn{5}{|l|}{ Wealth index } \\
\hline Most poor & 1 & & & \\
\hline Least poor & $1.3(0.8-2.0)$ & 0.323 & & \\
\hline \multicolumn{5}{|l|}{ Ethnicity by wealth Index } \\
\hline Maasai $\times$ most poor & 1 & & & \\
\hline Non Maasai x least poor & $2.8(1.1-7.2)$ & 0.038 & & \\
\hline \multicolumn{5}{|l|}{ Ethnicity by sex } \\
\hline Maasai x Males & & & 1 & \\
\hline Non Maasai x Female & & & $2.5(1.2-5.4)$ & 0.019 \\
\hline
\end{tabular}

Adjusted odds ratios (OR) and $95 \%$ confidence intervals $(\mathrm{Cl})$

outside the Arusha region . Statistically significant two way interaction occurred between ethnicity and district on DMFT, and between ethnicity and wealth index on dental fluorosis. Adolescents from non Maasai and Longido district were 3.9 ( $\mathrm{OR}=3.9, \mathrm{CI} 1.3-12.2)$ times more likely to have DMFT $>0$ in comparison with those from Maasai and Monduli district. Also non Maasai adolescents and being from least poor families were 0.1 $(\mathrm{OR}=0.1$, CI 0.04-0.3) times less likely to have dental fluorosis compared to Maasais and from most poor families. As shown in Table 7, non-Maasai adolescents and adolescents of mothers with high education level were $2.0(\mathrm{OR}=2.0$, CI $1.3-3.2)$ and $2.3(\mathrm{OR}=2.3$, CI 1.3-4.0) times more likely to have dental erosion than Maasai adolescents and adolescents from mothers with low education level, respectively. No cuppings were observed on occlusal surfaces of first molars. Considering $\mathrm{TMD}$, adolescents from Longido district $(\mathrm{OR}=0.2$, CI 0.1-0.4) were 0.2-times less likely to have TMD compared to those from Monduli district. Also adolescents from mothers with high education $(\mathrm{OR}=5.1, \mathrm{CI} 2.5-10.2)$ were more likely to have TMD compared to those from mothers with low education. Regarding TMD, statistically significant two way interaction occurred between ethnicity and district where non Maasai adolescents and being from Longido district were $3.4(\mathrm{OR}=3.4$, CI $1.1-10.4)$ times more likely to have TMD compared to those from Maasai and being from Monduli district.

\section{Discussion}

To our knowledge, this is the first study reporting on the prevalence, severity and socio-demographic distribution of oral diseases and conditions affecting Tanzanian school adolescents living in Maasai population areas of Monduli and Longido districts. According to the present findings, poor oral hygiene and gingival bleeding on gentle probing was common in the study group as a whole, whereas both severity and prevalence of dental caries prevalence seemed to be quite marginal. Moreover, about half the study group presented with sever dental fluorosis whereas the presence of erosion, tooth wear and TMD symptoms were rare. 
Table 6 Dental caries and dental fluorosis regressed on socio-demographic characteristics and statistically significant interactions

\begin{tabular}{|c|c|c|c|c|}
\hline \multirow[t]{2}{*}{ Variable } & \multicolumn{2}{|c|}{ Dental caries (DMFT >0) } & \multicolumn{2}{|c|}{ Dental fluorosis (TF grade 5-9) } \\
\hline & OR $(95 \% \mathrm{Cl})$ & $P$ & OR $(95 \% \mathrm{Cl})$ & $P$ \\
\hline \multicolumn{5}{|l|}{ District } \\
\hline Monduli & & & 1 & \\
\hline Longido & & & $0.1(0.1-0.3)$ & $<0.001$ \\
\hline \multicolumn{5}{|l|}{ Sex } \\
\hline \multicolumn{5}{|l|}{ Male } \\
\hline \multicolumn{5}{|l|}{ Female } \\
\hline \multicolumn{5}{|l|}{ Age group } \\
\hline $12-14$ years & 1 & & 1 & \\
\hline $15-17$ years & $2.0(1.1-3.5)$ & 0.017 & $1.4(0.9-2.3)$ & 0.171 \\
\hline \multicolumn{5}{|l|}{ Region of birth } \\
\hline Others & & & 1 & \\
\hline Arusha & & & $3.2(1.0-10.2)$ & 0.044 \\
\hline \multicolumn{5}{|l|}{ Ethnic groups } \\
\hline Maasai & 1 & & 1 & \\
\hline Non-Maasai & $2.2(1.1-4.1)$ & 0.018 & $0.9(0.5-1.8)$ & 0.767 \\
\hline \multicolumn{5}{|l|}{ Wealth index } \\
\hline Most poor & & & 1 & \\
\hline Least poor & & & $1.0(0.7-1.4)$ & 0.880 \\
\hline \multicolumn{5}{|l|}{ Ethnicity by district } \\
\hline Maasai x Monduli & 1 & & & \\
\hline Non-Maasai x Longido & $3.9(1.3-12.2)$ & 0.018 & & \\
\hline \multicolumn{5}{|l|}{ Ethnicity by wealth index } \\
\hline Maasai $x$ most poor & & & 1 & \\
\hline Non-Maasai x Least poor & & & $0.1(0.04-0.3)$ & $<0.001$ \\
\hline
\end{tabular}

Adjusted odds ratios (OR) and 95\% confidence intervals (CI)

In this study, poor oral hygiene was found to be more common than in other comparable studies from sub-Saharan Africa since about $66 \%$ of the school adolescents investigated showed bad oral hygiene compared to only $32-45 \%$ reported earlier for instance in Tanzania and Nigeria [58-60]. Consistent with the sex distribution of oral hygiene observed in this study, where girls were twice as likely as boys to have good oral hygiene status, this finding is in agreement with several other studies from Nigeria (10-19 year olds) [61], Kenya (12 year olds) [62] and India (7-12 year olds) [63]. Contrary to these findings, one urban study in Tanzania ( 15 year olds) found that poor oral hygiene status was equally distributed between girls and boys [60]. A large proportion of the adolescents (41\%) investigated showed gingival bleeding on gentle probing, a sign of gingivitis. This prevalence is lower than the one reported in 12 year old children in Uganda where about $54 \%$ of the participants presented with gingival bleeding [17].

The mean DMFT (0.13) in our study was low and in agreement with other studies from East Africa [19-21].
As expected, the prevalence of dental caries in this study was significantly higher in older than in younger age groups $[15-17,64,65]$. The decayed component (D) of the DMFT- index in our study constituted $90 \%$, and the missing component $(\mathrm{M})$ was $10 \%$. It is noteworthy that none of the participants in this study was diagnosed with any type of dental restoration. The lack of dental restorations has earlier been reported on from other studies in sub-Saharan Africa [2, 20, 66] and may be an indicator of limited professional oral health services and poor socioeconomic situation prevailing in this area. The finding that Maasai adolescents had less dental caries compared to non-Maasai adolescents, is also in agreement with previous findings dateing as far back as 1931 but also 1997 [22, 23].

As expected, due to the high fluoride content in the drinking water [67-69], severe dental fluorosis (TF grade 5-9) was common and presented in nearly half of the participants (48.6\%). This is also in accordance with earlier findings from Kenya [32] but contrary to other studies from Tanzania and Ethiopia $[33,70]$ where a lower prevalence of 
Table 7 Dental erosion, tooth wear and TMD regressed on socio-demographic characteristics and statistically significant interactions

\begin{tabular}{|c|c|c|c|c|c|c|}
\hline \multirow[t]{2}{*}{ Variable } & \multicolumn{2}{|c|}{ Dental erosion (Grade 1-3) } & \multicolumn{2}{|c|}{ Tooth wear (Grade 1-4) } & \multicolumn{2}{|c|}{ TMD $(2 \mathrm{Q} / \mathrm{TMD}>0)$} \\
\hline & OR $(95 \% \mathrm{Cl})$ & $P$ & $\mathrm{OR}(95 \% \mathrm{Cl})$ & $P$ & $\mathrm{OR}(95 \% \mathrm{Cl})$ & $P$ \\
\hline \multicolumn{7}{|l|}{ District } \\
\hline Monduli & 1 & & & & 1 & \\
\hline Longido & $1.6(0.9-3.2)$ & 0.140 & & & $0.2(0.1-0.4)$ & $<0.001$ \\
\hline \multicolumn{7}{|l|}{ Sex } \\
\hline Female & & & & & 1 & \\
\hline Male & & & & & $1.2(0.7-2.2)$ & 0.483 \\
\hline \multicolumn{7}{|l|}{ Age group } \\
\hline $12-14$ years & & & & & 1 & \\
\hline $15-17$ years & & & & & $1.3(0.8-2.2)$ & 0.251 \\
\hline \multicolumn{7}{|l|}{ Region of birth } \\
\hline Others & 1 & & 1 & & & \\
\hline Arusha & $1.1(0.5-2.3)$ & 0.897 & $1.3(0.9-1.9)$ & 0.129 & & \\
\hline \multicolumn{7}{|l|}{ Ethnic groups } \\
\hline Maasai & 1 & & & & 1 & \\
\hline Non maasai & $2.0(1.3-3.2)$ & 0.003 & & & $1.6(0.9-2.9)$ & 0.096 \\
\hline \multicolumn{7}{|l|}{ Wealth index } \\
\hline Most poor & 1 & & 1 & & & \\
\hline Least poor & $0.9(0.6-1.2)$ & 0.455 & $0.8(0.7-1.1)$ & 0.157 & & \\
\hline \multicolumn{7}{|l|}{ Mother's education } \\
\hline Low ( $\leq$ primary school) & 1 & & & & 1 & \\
\hline High ( $\geq$ secondary school) & $2.3(1.3-4.0)$ & 0.002 & & & $5.1(2.5-10.2)$ & $<0.001$ \\
\hline \multicolumn{7}{|l|}{ Ethnicity by district } \\
\hline Maasai x Monduli & & & & & 1 & \\
\hline Non Maasai x Longido & & & & & $3.4(1.1-10.4)$ & 0.034 \\
\hline
\end{tabular}

Adjusted odds ratios (OR) and 95\% confidence intervals (CI)

severe dental fluorosis (10-34\%) has been reported. Identified sociodemographic covariates of dental fluorosis were location and region of birth. In this regard, previous studies from the Arusha region reported a fluoride concentration between $0.1-78.09 \mathrm{mg} / \mathrm{l}$ in drinking water $[67,68]$.

In the present study, dental erosion extending in to dentine was found only in $1.9 \%$ of the adolescents. This is lower than that found in other comparable studies from Saudi Arabia and Sweden which reported prevalence of 11.9 to $26.0 \%$ [36, 37]. The rural environment in which the adolescents in this study from both districts live in combination with a restricted economic situation and a reduced availability to shops might be limiting the access to erosive conducive products/challenges. Non-Maasai adolescents were more prone to have dental erosion than Maasai adolescents. This might be attributed to differences in exposure to risk factors for erosion between the two ethnic groups. Adolescents whose mothers had higher levels of education had an elevated risk to develop dental erosion than children whose mothers had low education. This finding is in agreement with some studies $[71,72]$ but in contradiction to other studies $[73,74]$. The relationship between the mother's high level of education and the presence of dental erosion in the children in this study may be due to the wealth and lifestyle of such a family and thereby greater chances for the children to consume erosive conducive products.

This study revealed that $16.5 \%$ of the adolescents had tooth wear extending into dentine. This is contrary to findings from England where a higher prevalence (30.0-53.0\%) has been reported $[75,76]$ and also contrary to findings from China, Nigeria, which found lower prevalence rates (1.9-8.5\%) [77, 78]. Regression analysis revealed no sociodemographic variable that was significantly correlated with tooth wear. Thus, non of the socio-demographic factors of importance for the development of tooth wear was included in the present analysis.

Comparing studies using a similar diagnostic system (TMD-p, RDC/TMD), the prevalence of adolescents with TMD pain in this study was $11.8 \%$ which is slightly higher than in other previous studies in Sweden and United States of America [45, 79-81], but also lower than other previous studies in Saudi Arabia and China [46, 79]. 
Psychosocial factors, for example stress related behaviors, are considered to be a common cause for development of TMD [82]. It was expected that in a nomadic society, this impact would be low and thus lessen the occurrence of reported TMD, but instead the prevalence of TMD was higher than in comparable studies performed in Western societies. This variation in TMD magnitude could be because of the differences related to heterogeneous age groups, the sample size and the setting of sample selection [83]. This study identified adolescents from Monduli district and adolescents of mothers with high education to be more likely to have TMD pain. This may imply that environmental and cultural factors may have a great role in the development of TMD among adolescents. One American study reported similar findings, that the geographical study site was independently associated with TMD [84]. However, our finding is contrary to the findings from China, which found that children and adolescents with lower parental educational levels or household income, had higher rates of TMD pain [79]. Similar findings on correlation between low educational level and other types of pain has also been reported on $[85,86]$. The correlation between high education level of the mother and TMD in our study may be due to subgroup differences in emotional responsivity to chronic pain as well as pain intensity within a group of individuals [86]. However, further investigations are needed to clarify the association between mother's education level and TMD in this particular society.

\section{Study limitations}

The cross-sectional method utilized in data collection, has some drawbacks as it is difficult to establish a causal relationship. The information on oral health was collected by interviews/clinical examination conducted by trained medical/dental personnel. Information bias, recall bias and social desirability bias might have been introduced due to the self-report method employed. In addition, fewer male than female adolescents and school non-attenders in our total study sample, might have contributed to a selection bias that could have affected the study findings and generalization. Relatively fewer males than females in our study sample might be due to the fact that, in their setting male adolescents are responsible for taking care of their livestock, as a result some do not attend schools at all and some start attending schools very late age-wise. Although the methods used in this study have been utilized in other studies in East Africa [60, 87], precautious interpretation should be employed in extrapolating these findings into other societies in Tanzania, but it can be useful in other Maasai population areas in the country, especially for adolescents attending primary schools. There is a need for conducting longitudinal studies in order to further assess the sociodemographic risk indicators in this society and to explore the direction of the relationships identified.

\section{Conclusion}

The study showed that oral diseases/conditions like dental caries and dental erosion were less common, but gingival bleeding, dental fluorosis, tooth wear and TMD were common findings in adolescents attending primary schools in the Maasai population areas in Tanzania. Notable differences between Maasai and non-Maasai ethnic groups and certain correlations to sociodemographic factors were detected. Our findings can be utilized by policy makers in the planning of oral health programs in all public primary schools of Maasai population areas of Tanzania in order to address oral diseases/conditions in this area.

\section{Abbreviations}

2Q/TMD: 2 epidemiological Questions on Temporomandibular Disorder;

Cl: Confidence Interval; CI-S: Simplified Calculus Index; DI-S: Simplified Debris Index; DMFS: Decayed Missing Filled Surfaces; DMFT: Decayed Missing Filled Tooth; DMT: Decayed Missing Tooth; GBI: Gingival Bleeding Index; OHIS: Simplified Oral Hygiene Index; OR: Odds Ratio; RDC: Research Diagnostic Criteria; SD: Standard Deviation; SPSS: Statistical Package for Social Sciences; TF-index: Thylstrup-Fejerskov-index; TMD: Temporomandibular Disorder; TMDp: Temporomandibular Disorder pain; WHO: World Health Organisation

\section{Acknowledgements}

We would like to thank the district education officers of both Monduli and Longido district councils for field work support. Thanks to Rose Lukumay and Ciriel Palanjo who were responsible for the data collection in Monduli district and to Joyce Mwanga and Wema Laizer who collected data in Longido district. We also give our sincere thanks to parents, teachers and study participants for making this study happen.

\section{Funding}

The research was fully funded by Department of Clinical Dentistry, University of Bergen, Norway. The funding body didn't play any role in the design of the study and collection, analysis, and interpretation of data and in writing the manuscript.

\section{Availability of data and materials}

The datasets used and/or analysed during the current study are available from the corresponding author on request.

\section{Authors' contributions}

LS principal investigator, designed the study, collected the data, performed the statistical analyses, and wrote the manuscript. ANA co-supervisor, designed the study, guided the statistical analyses and writing the manuscript. AJ participated in the design of the study, guided the statistical analyses and writing the manuscript. IK co-supervisor, participated in the design of the study and provided valuable guidance in the data collection and writing the manuscript. AGJ main supervisor, designed the study, guided the statistical analyses and writing the manuscript. All authors read and approved the final manuscript.

\section{Authors' information \\ LS: PhD candidate, Department of Clinical Dentistry, University of Bergen, Norway. \\ ANA: Professor, Department of Clinical Dentistry, University of Bergen, Norway. AJ: Professor, Department of Clinical Dentistry, University of Bergen, Norway. IK: Senior Lecturer, Muhimbili University of Health and Allied Sciences, Dar Es salaam, Tanzania. \\ AGJ: Professor, Department of Clinical Dentistry, University of Bergen, Norway.}

Ethics approval and consent to participate

Ethical clearance was obtained prior to study from the ethical research committee in Norway (REK VEST, reference number 2015/2477) and the 
Medical Research Coordinating Committee of Ministry of Health and Social Welfare in Tanzania (reference number NIMR/HQ/R.8a/VOL.IX/2214). Permission to work with primary school children/adolescents was obtained from Ministry of Education and Vocational Training through Monduli and Longido district councils and their respective educational authorities. Participation was voluntary and without compensation. Prior to the participation, informed signed /verbal consent was obtained by all participants and their parents. If needed relevant advice and/or referral to the district hospital were given free of charge.

\section{Consent for publication}

Not applicable

\section{Competing interests}

The authors declare that they have no competing interests.

\section{Publisher's Note}

Springer Nature remains neutral with regard to jurisdictional claims in published maps and institutional affiliations.

\section{Author details}

'Department of Clinical Dentistry Cariology, Faculty of Medicine, University of Bergen, Bergen, Norway. ${ }^{2}$ Department of Clinical Dentistry Community Dentistry, Faculty of Medicine, University of Bergen, Bergen, Norway. ${ }^{3}$ Department of Clinical Dentistry Prosthodontics, Faculty of Medicine, University of Bergen, Bergen, Norway. ${ }^{4}$ Department of Restorative Dentistry, School of Dentistry, Muhimbili University of Health and Allied Sciences, Dar Es Salaam, Tanzania.

\section{Received: 17 February 2018 Accepted: 13 November 2018} Published online: 04 December 2018

\section{References}

1. World Dental Federation (FDI). Oral health worldwide. A report by FDI world dental federation. 2014. Available at: https://www.cugh.org/sites/default/ files/FDIWhitePaper_OralHealthWorldwide.pdf. Accessed 12 May 2017.

2. Mafuvadze BT, Mahachi L, Mafuvadze B. Dental caries and oral health practice among 12 year old school children from low socio-economic status background in Zimbabwe. Pan Afr Med J. 2013;14:164.

3. Petersen PE. Improvement of oral health in Africa in the 21 st century- the role of the WHO global Oral health Programme. Dev Dent. 2004;5:1.

4. Young A. Current research on health among Tanzanian pastoralists, and future directions for improving pastoral health in East Africa. http://www. academia.edu/351573/Current_research_on_health_among_Tanzanian_ pastoralists_and_future_directions_for_improving_pastoral_health_in_East_ Africa. Accessed 12 May 2017.

5. Correa-Faria P, Martins-Junior PA, Vieira-Andrade RG, Marques LS, RamosJorge ML. Factors associated with the development of early childhood caries among Brazilian preschoolers. Braz Oral Res. 2013;27(4):356-62.

6. Lopes RM, Domingues GG, Junqueira SR, Araujo ME, Frias AC. Conditional factors for untreated caries in 12-year-old children in the city of Sao Paulo. Braz Oral Res. 2013;27(4):376-81.

7. Nicolau B, Marcenes W, Hardy R, Sheiham A. A life-course approach to assess the relationship between social and psychological circumstances and gingival status in adolescents. J Clin Periodontol. 2003;30(12):1038-45.

8. Gushi LL, Soares Mda C, Forni TI, Vieira V, Wada RS, Sousa Mda L. Relationship between dental caries and socio-economic factors in adolescents. J Appl Oral Sci. 2005;13(3):305-11.

9. Oliveira LB, Sheiham A, Bonecker M. Exploring the association of dental caries with social factors and nutritional status in Brazilian preschool children. Eur J Oral Sci. 2008;116(1):37-43.

10. Watt RG, Sheiham A. Integrating the common risk factor approach into a social determinants framework. Community Dent Oral Epidemiol. 2012;40(4): 289-96.

11. Edelstein BL. Disparities in oral health and access to care: findings of national surveys. Ambul Pediatr. 2002;2(Suppl 2):141-7.

12. Auad SM, Waterhouse PJ, Nunn JH, Moynihan PJ. Dental caries and its association with sociodemographics, erosion, and diet in schoolchildren from Southeast Brazil. Pediatr Dent. 2009;31(3):229-35.
13. de Oliveira TC, da Silva DA, Leite de Freitas YN, da Silva RL, Pegado CP, de Lima KC. Socio-demographic factors and oral health conditions in the elderly: a population-based study. Arch Gerontol Geriatr. 2013;57(3):389-97.

14. Moimaz SA, Fadel CB, Lolli LF, Garbin CA, Garbin AJ, Saliba NA. Social aspects of dental caries in the context of mother-child pairs. J Appl Oral Sci. 2014;22(1):73-8.

15. Rwenyonyi CM, Muwazi LM, Buwembo W. Assessment of factors associated with dental caries in rural communities in Rakai District, Uganda. Clin Oral Investig. 2011;15(1):75-80.

16. Kutesa A, Kasangaki A, Nkamba M, Muwazi L, Okullo I, Rwenyonyi CM. Prevalence and factors associated with dental caries among children and adults in selected districts in Uganda. Afr Health Sci. 2015;15(4):1302-7.

17. Muwazi LM, Rwenyonyi CM, Tirwomwe FJ, Ssali C, Kasangaki A, Nkamba ME, Ekwaru P. Prevalence of oral diseases/conditions in Uganda. Afr Health Sci. 2005;5(3):227-33.

18. Varenne B, Petersen PE, Ouattara S. Oral health status of children and adults in urban and rural areas of Burkina Faso, Africa. Int Dent J. 2004;54(2):83-9.

19. Mashoto KO, Anne N Astrom AN, Skeie MS, Masalu JR. Socio-demographic disparity in oral health among the poor: a cross sectional study of early adolescents in Kilwa district, Tanzania. BMC Oral health. 2010;10:7.

20. Gathecha G, Makokha A, Peter Wanzala P, Omolo J, Smith P. Dental caries and oral health practices among 12 year old children in Nairobi west and Mathira west districts, Kenya. Pan Afr Med J. 2012;12:42.

21. Wandera M, Twa-Twa J. Baseline survey of oral health of primary and secondary school pupils in Uganda. Afr Health Sci. 2003;3(1):19-22.

22. Sally F, Enig MG. Out of Africa: what Dr. Price and Dr. Burkett discovered in their studies of sub-Saharan tribes. PPNF Health J. 1997;21(1):1-5.

23. Boyd-Orr JBO, Gilks JL. Studies of nutrition. The physique and health of two African tribes. London: HM Stationery off; 1931.

24. Goel R, Vedi A, Veeresha KL, Sogi GM, Gambhir RS. Oral hygiene practices and dental caries prevalence among 12 \& 15 years school children in Ambala, Haryana -a cross-sectional study. J Clin Exp Dent. 2015;7(3):e374-9.

25. World Health Organization (WHO). WHO information series on school health, Doc 11: Oral health promotion through schools. Geneva: WHO; 2003. http:// new.paho.org/hq/dmdocuments/2009/OH_st_sch.pdf. Accessed 26 Aug 2017

26. Siziya S, Muula AS, Rudatsikira E. Self-reported poor oral hygiene among inschool adolescents in Zambia. BMC Res Notes. 2011;4:255.

27. Kolawole KA, Oziegbe EO, Bamise CT. Oral hygiene measures and the periodontal status of school children. Int J Dent Hyg. 2011;9(2):143-8.

28. Lembariti BS, Frencken JE, Pilot T. Prevalence and severity of periodontal conditions among adults in urban and rural Morogoro, Tanzania. Community Dent Oral Epidemiol. 1988;16(4):240-3.

29. Mumghamba EG, Markkanen HA, Honkala E. Periodontal status and treatment needs in a rural area of Ukonga, Tanzania. Int Dent J. 1996;46(3): 156-60.

30. Kahama RW, Kariuki DN, Kariuki HN, Njenga LW. Fluorosis in children and sources of fluoride around lake Elementaita region of Kenya. Fluoride. 1997; 30(1):19-25.

31. Vuhahula EAM, Masalu JRP, Mabelya L, Wandwi WBC. Dental fluorosis in Tanzania great Rift Valley in relation to fluoride levels in water and in 'Magadi' (Trona). Desalination. 2009;248(1-3):610-5.

32. Makhanu M, Opinya G, Mutave RJ. Dental fluorosis, caries experience and snack intake of 13-15 year olds in Kenya. East Afr Med J. 2009;85(3):120-4.

33. Awadia AK, Bjorvatn K, Birkeland JM, Haugejorden O. Weaning food and magadi associated with dental fluorosis in northern Tanzania. Acta Odontol Scand. 2000;58(1):1-7.

34. Bardolia P, Burnside G, Ashcroft A, Milosevic A, Goodfellow SA, Rolfe EA Pine CM. Prevalence and risk indicators of erosion in thirteen- to fourteenyear-olds on the Isle of Man. Caries Res. 2010;44(2):165-8.

35. Arnadottir IB, Saemundsson SR, Holbrook WP. Dental erosion in Icelandic teenagers in relation to dietary and lifestyle factors. Acta Odontol Scand. 2003;61(1):25-8.

36. Al-Majed I, Maguire A, Murray JJ. Risk factors for dental erosion in 5-6 year old and 12-14 year old boys in Saudi Arabia. Community Dent Oral Epidemiol. 2002;30(1):38-46.

37. Hasselkvist A, Johansson A, Johansson AK. Dental erosion and soft drink consumption in Swedish children and adolescents and the development of a simplified erosion partial recording system. Swed Dental J. 2010;34(4):187-95.

38. Al-Ashtal A, Johansson A, Omar R, Johansson AK. Dental erosion in groups of Yemeni children and adolescents and the modification of an erosion partial recording system. Int J Paediatr Dent. 2017;27(4):283-92. 
39. Khalifa N, Allen PF, Abu-bakr NH, Abdel-Rahman ME, Abdelghafar KO. A survey of oral health in a Sudanese population. BMC Oral Health. 2012;12:5.

40. Ibiyemi O, Oketade IO, Taiwo JO, Oke GA. Oral habits and tooth wear lesions among rural adult males in Nigeria. Arch Orofac Sci. 2010;5(2):31-5.

41. Manfredini D, Guarda-Nardini L, Winocur E, Piccotti F, Ahlberg J, Lobbezoo F. Research diagnostic criteria for temporomandibular disorders: a systematic review of axis I epidemiologic findings. Oral Surg Oral Med Oral pathol Oral Radiol Endod. 2011;112(4):453-62.

42. Otuyemi OD, Owotade FJ, Ugboko VI, Ndukwe KC, Olusile OA. Prevalence of signs and symptoms of temporomandibular disorders in young Nigerian adults. J Orthod. 2000;27(1):61-5.

43. Fabian FM, Mumghamba EG. Risk factors for signs and symptoms of TMD in a rural adult southeast Tanzanian population. Cranio. 2008;26(1):44-9.

44. Kohler AA, Nydell HA, Magnusson T, Hugoson A. Prevalence of symptoms and signs indicative of temporomandibular disorders in children and adolescents. A cross-sectional epidemiological investigation covering two decades. Eur Arch Paediatr Dent. 2009:10(1):16-25.

45. List T, Wahlund K, Wenneberg B, Dworkin SF. TMD in children and adolescents: prevalence of pain, gender differences, and perceived treatment need. J Orofac Pain. 1999;13(1):9-20.

46. Al-Khotani A, Naimi-Akbar A, Albadawi E, Ernberg M, Hedenberg-Magnusson B, Christidis N. Prevalence of diagnosed temporomandibular disorders among Saudi Arabian children and adolescents. J Headache Pain. 2016;17:41.

47. Casanova-Rosado JF, Medina-Solís CE, Vallejos-Sánchez AA, CasanovaRosado AJ, Hernández-Prado B, Avila-Burgos L. Prevalence and associated factors for temporomandibular disorders in a group of Mexican adolescents and youth adults. Clin Oral Investig. 2006;10(1):42-9.

48. Schellenberg JA, Victora CG, Mushi A, de Savigny D, Schellenberg D, Mshinda $\mathrm{H}$, Bryce J. Inequities among the very poor: health care for children in rural southern Tanzania. Lancet. 2003;361(9357):561-6.

49. McKenzie DJ. Measuring inequality with asset indicators. J Popul Econ. 2005;18:229.

50. Nilsson IM, List T, Drangsholt M. The reliability and validity of self-reported temporomandibular disorder pain in adolescents. J Orofac Pain. 2006;20(2): $138-44$

51. Greene JC, Vermillion JR. The simplified oral hygiene index. JADA. 1964;68: 7-13.

52. Ainamo J, Bay I. Problems and proposals for recording gingivitis and plaque. Inter Dent J. 1975;25(4):229-35.

53. World Health Organization (WHO). Oral health surveys: basic methods. 5th ed. Geneva: WHO; 2013. http://www.who.int/oral_health/publications/ 9789241548649/en/. Accessed 26 Aug 2017

54. Thylstrup A, Fejerskov O. Clinical appearance of dental fluorosis in permanent teeth in relation to histologic changes. Community Dent Oral Epidemiol. 1978;6(6):315-28.

55. Johansson AK, Johansson A, Birkhed D, Omar R, Baghdadi S, Carlsson GE. Dental erosion, soft-drink intake, and oral health in young Saudi men, and the development of a system for assessing erosive anterior tooth wear. Acta Odontol Scand. 1996:54(6):369-78.

56. Carlsson GE, Johansson A, Lundqvist S. Occlusal wear: a follow-up study of 18 subjects with extensively worn dentitions. Acta Odontol Scand. 1985; 43(2):83-90

57. Tang W, Hu J, Zhang H, Wu P, He H. Kappa coefficient: a popular measure of rater agreement. Shanghai Arch Psychiatry. 2015;27(1):62-7.

58. Mtaya M, Brudvik P, Åstrøm AN. Prevalence of malocclusion and its relationship with socio-demographic factors, dental caries, and oral hygiene in 12- to 14-year-old Tanzanian schoolchildren. Eur J Orthod. 2009;31(5): $467-76$

59. Azodo CC, Amenaghawon OP. Oral hygiene status and practices among rural dwellers. European J Gen Dent. 2013;2(1):42-5.

60. Mbawalla HS, Masalu JR, Åstrøm AN. Socio-demographic and behavioural correlates of oral hygiene status and oral health related quality of life, the Limpopo - Arusha school health project (LASH): a cross-sectional study. BMC Pediatr. 2010;10:87.

61. Osonwa KO, Eko EJ. A comparative study on oral hygiene practices among school adolescent in a public and private school within Ogoja urban in Ogoja local government area of cross river state, Nigeria. Int J Educ Res. 2015;3:2.

62. Hideki F, Cyril NO, Eunice K, Wagaiyu EG, Yoshihiko H. Oral health status among 12-year-old children in a rural Kenyan community. J Dent Oral Health. 2014;1:1-5.
63. Minor Babu MS, Nirmala SVSG, Sivakumar N. Oral hygiene status of 7-12 year old school children in rural and urban population of Nellore district. J Indian Assoc of Public Health Dent. 2011;18(Suppl 3):1075-80.

64. Sofola OO, Jeboda SO, Shaba OP. Dental caries status of primary school children aged 4-16 years in Southwest Nigeria. Odontostomatol Trop. 2004; 27(108):19-22.

65. Mohammadi S, Prashant G, Naveen KP, Sushanth V, Imranulla M. Dental caries status in 6-14-year-old schoolchildren of rural Channagiri, Davangere: a cross-sectional survey. J Indian Assoc Public Health Dent. 2015;13(4):389-92.

66. Bajomo AS, Rudolph MJ, Ogunbodede EO. Dental caries in six, 12 and 15 year old Venda children in South Africa. East Afr Med J. 2004;81(5):236-43.

67. Awadia AK, Haugejorden O, Bjorvatn K, Birkeland JM. Vegetarianism and dental fluorosis among children in a high fluoride area of northern Tanzania. Int J Paediatr Dent. 1999;9(1):3-11.

68. Mjengera $\mathrm{H}$. Excess fluoride in potable water in Tanzania and the defluoridation technology with emphasis on the use of polyaluminium chloride and magnesite. 1988. https://www.ircwash.org/sites/default/ files/257-4796.pdf. Accessed 22 June 2017.

69. Olsson B. Dental findings in high-fluoride areas in Ethiopia. Community Dent Oral Epidemiol. 1979;7(1):51-6.

70. Wondwossen F, Åstrøm AN, Bjorvatn K, Bårdsen A. Sociodemographic and behavioural correlates of severe dental fluorosis. Int J Paediatr Dent. 2006;16(2):95-103.

71. Luo Y, Zeng XJ, Du MQ, Bedi R. The prevalence of dental erosion in preschool children in China. J Dent. 2005;33(2):115-21.

72. Mangueira DF, Sampaio FC, Oliveira AF. Association between socioeconomic factors and dental erosion in Brazilian schoolchildren. J Public Health Dent. 2009;69:254-9.

73. Wang $\mathrm{P}$, Lin HC, Chen JH, Liang HY. The prevalence of dental erosion and associated risk factors in 12-13-year-old school children in southern China. BMC Public Health. 2010;10:478.

74. Al-Malik MI, Holt RD, Bedi R. The relationship between erosion, caries and rampant caries and dietary habits in preschool children in Saudi Arabia. Int J Paediatr Dent. 2001;11(6):430-9.

75. Bardsley PF, Taylor S, Milosevic A. Epidemiological studies of tooth wear and dental erosion in 14-year-old children in north West England. Part 1: the relationship with water fluoridation and social deprivation. Br Dent J. 2004; 197(7):413-6.

76. Milosevic A, Young PJ, Lennon MA. The prevalence of tooth wear in 14year-old school children in Liverpool. Community Dent Health. 1994;11(2): 83-6.

77. Ogunyinka A, Dosumu OO, Otuyemi OD. The pattern of toothwear amongst 12-18-year-old students in a Nigerian population. J Oral Rehabil. 2001;28(6): $601-5$.

78. Zhang J, Du Y, Wei Z, Tai B, Jiang H, Du M. The prevalence and risk indicators of tooth wear in 12- and 15-year-old adolescents in Central China. BMC Oral Health. 2015;15(1):120.

79. Hongxing L, Astrom AN, List T, Nilsson IM, Johansson A. Prevalence of temporomandibular disorder pain in Chinese adolescents compared to an age-matched Swedish population. J Oral Rehabilit. 2016;43(4):241-8

80. Nilsson IM, List T, Drangsholt M. Prevalence of temporomandibular pain and subsequent dental treatment in Swedish adolescents. J Orofac Pain. 2005;19(2):144-50

81. LeResche L, Mancl LA, Drangsholt MT, Huang G, Von Korff M. Predictors of onset of facial pain and temporomandibular disorders in early adolescence. Pain. 2007:129(3):269-78.

82. Durham J, Raphael KG, Benoliel R, Ceusters W, Michelotti A, Ohrbach R. Perspectives on next steps in classification of oro-facial pain - part 2: role of psychosocial factors. J Oral Rehabil. 2015:42(12):942-55.

83. De Sena MF, de Mesquita KSF, Santos FRR, Silva FWGP, Serrano KVD Prevalence of temporomandibular dysfunction in children and adolescents. Rev Paul Pediatr. 2013;31(4):538-45

84. Bair E, Ohrbach R, Fillingim RB, Greenspan JD, Dubner R, Diatchenko L, Helgeson E, Knott C, Maixner W, Slade GD. Multivariable modeling of phenotypic risk factors for first-onset TMD: the OPPERA prospective cohort study. J Pain. 2013;14(12):T102-15. 
85. Slade GD, Bair E, Greenspan JD, Dubner R, Fillingim RB, Diatchenko L, Maixner W, Knott C, Ohrbach R. Signs and symptoms of first-onset TMD and sociodemographic predictors of its development: the OPPERA prospective cohort study. J Pain. 2013;14(12):T20-32.e21-3.

86. Bates MS, Rankin-Hill L. Control, culture and chronic pain. Soc Sci Med. 1994;39(5):629-45.

87. Masumo R, Bardsen A, Mashoto K, Astrom AN. Prevalence and sociobehavioural influence of early child hood caries, ECC, and feeding habits among 6-36 months old children in Uganda and Tanzania. BMC Oral Health. 2012;12:24

Ready to submit your research? Choose BMC and benefit from:

- fast, convenient online submission

- thorough peer review by experienced researchers in your field

- rapid publication on acceptance

- support for research data, including large and complex data types

- gold Open Access which fosters wider collaboration and increased citations

- maximum visibility for your research: over $100 \mathrm{M}$ website views per year

At BMC, research is always in progress.

Learn more biomedcentral.com/submissions 